\title{
Interfaced multidirectional small-scaled modules for intralogistic operation
}

\author{
Prof. Dr.-Ing. Ludger Overmeyer \\ Institut für Transport- und Automatisierungstechnik \\ Gottfried Wilhelm Leibniz Universität Hannover \\ Dipl.-Ing. Kai Ventz \\ Transnorm System GmbH, Harsum \\ Dipl.-Ing. Sascha Falkenberg \\ Institut für Transport- und Automatisierungstechnik \\ Gottfried Wilhelm Leibniz Universität Hannover
}

\begin{abstract}
This article examines options of an innovative design of intralogistic systems by interfacing small-scaled modules. Current intralogistic systems are quite customized with unique solutions and small production lots. In most cases these systems feature a central main control. To offer highly individual solutions, thus meeting the demand of shorter life cycles, there is a need for more flexible material handling systems. Hence, identical smallscaled modules with integrated intelligence present a promising approach. Requirements and options are analyzed to develop a small-scaled module as a basis for a flexible intralogistic system. An essential requirement for a small sized module is functional flexibility to allow configuring individual intralogistic solutions. Thus, these modules have to combine a variety of functions to provide not only a material flow function but also sorting and distributing functions, for instance. Furthermore, an easy extension of the system in any plane direction should be possible. Approaches based on existing technology, such as roller conveyors or belt conveyors are considered along with new solutions concerning this ambitious challenge. A further development of swivel wheel technology and some new ideas like a swivel disk present promising solutions. With a flexible mechanical solution we can design modules that can be developed into self controlling elements.
\end{abstract}

\section{Introduction}

In-plant material handling as part of the intralogistics industry offers an enormous rationalization potential to all industries [ARN 06, WOL 07]. The requirements of a materials handling system become more complex from the mechanical point of view concerning the material to be conveyed, functionality as well as the system control. Very different materials to be conveyed - from smallest not packed parts to large cardboards and containers, which together use one conveyor system - place high demands on a material handling system.

Functionalities are customized particularly to a given application, ranging from pure transport to complex assortment and transfer functions, like for fully automatic storage warehouses or goods commissioning, for example. Usually the common material flow systems used today are controlled principally by programmable control system.. The position of the material to be conveyed is determined e.g. by optical sensor systems such as light barriers. Trackings and tracings are calculated by the programmable control system so that assortment procedures are introduced as needed. These systems are mechanically predefined and therefore functionalities like sorting or transferring are locally bound in the system. Such functionalities are usually designed for the largest material to be conveyed which can be handled by the system and usually resulting in less performance for smaller materials to be conveyed. Layout changes require considerable effort. A new trend-setting material handling solution must meet individual complex tasks of transportation with implemented intelligence and be flexible enough for changes and adjustments with low investment costs.

Similarly, small-scaled material flow components with integrated control and data processing provide a solution. In combination, these single modules solve complex material flow tasks and promise cost advantages by their similar design. On one hand the homogeneity of elements applied will decrease production costs by an increased number of uniform items. On the other hand advantages of standardised interfaces lead to reduced planning and installation effort.

Operating an intralogistic plant maintenance, its repair and functional flexibility play a substantial role. At the moment this is realized by exchanging both specific elements and expensive local assembly works. Inexpensive small-scaled modules permit a simplified exchange of entire modules without complex assembly and adjustment work.

An important aspect of the modularity is the design of individual decentralized intelligence instead of a central control system hierarchy, since the potential of modularity can be used best with autonomous units. Approaches of decentralized modular components are realized and described in [DEM 08, TRA 08]. Decentralized structures 
such as the internet or behavior patterns in nature (comparable to social behavior of groups) serve as a model for the development of new control systems [OVE 07]. Individual interactions can result in a profitable whole; take ant cultures as an example. A lack of hierarchy and the high resilience and reliability are main characteristics of these systems. The controlling intelligence or logic is distributed among the elements of the system and the overall system can be expanded almost indefinitely.

Self-controlling material flow processes are described amongst others in [HOM 06].

The "internet of things" applying RFID technology is based on a decentralized intelligence distributed on the material flow elements [SEI 05, FLE 05, OVE 05]. The material to be conveyed can influence its flow direction by communicating with the system, for example by means of RFID labels which are detected and selected by conveyors or at transfers in order to direct the materials and goods through the system. As a result a flexible routing can be arranged. Standardized interfaces on similar modules are necessary which significantly reduce planning and installation effort and costs.

The challenge is to develop small-scaled material flow modules which can be produced economically in high quantities. The interfacing of several modules will generate technical functionality by interaction effects like networking, for instance (Figure.1). Special focus during the design process of the modularity principle is put on lower weight class (GK1, up to $50 \mathrm{~kg} / 110 \mathrm{lbs}$ ) [DUB 05]. In this class the modularity principle in combination with a downsizing appears most promising.

\section{Requirements of a small-scaled conveyor module}

A small-scaled module needs to be developed which can be produced economically in high quantities. An interfacing of many similar modules thus generates a material flow system. Subtasking will be the investigation of the mechanics, the drive and the control systems as well as the communication among the modules. Questions about the functionality of a basic module depend very much on the functional purpose of the overall system. It is possible, for example, to implement basic modules as belt conveyor miniatures with conveyor operation in main flow direction (x-direction) with integrated control logic and interfaces to communicate amongst each other. The modular developed system offers all conceivable functions as accumulating in main flow direction $\mathrm{x}$. For functionalities in y-direction, like transferring and sorting functions, further or additional modules are necessary, which actually would bind this functionality locally into the system.

Modules with the possibility of material flow in $\mathrm{x}$ and $\mathrm{y}$-directions are more complex, regarding the design but the modularity is more consequent, however. Transfer and sorting functions are flexible and possible everywhere in the system. Depending on functional requirement of the overall system there are several options to develop a modular system. First, the mechanical functionality is analyzed. This is structured into three levels:.

1. Module with simple functional range

2. Modules with simple functional range extended by modules with special functionalities for transferring and sorting

3. Modules with extended functional range, multi directional modules

Modules with multi directional functionality offer the most flexibility. Table1 illustrates a comparison of concepts with different mechanical function range of the modules:

\begin{tabular}{|l|l|l|l|}
\hline & $\begin{array}{l}\text { modules with simple } \\
\text { functional range }\end{array}$ & $\begin{array}{l}\text { modules with simple } \\
\text { functional range extended by } \\
\text { modules with special } \\
\text { functionalities for transferring } \\
\text { and sorting }\end{array}$ & $\begin{array}{l}\text { modules with extended } \\
\text { functional range, multi } \\
\text { directional modules }\end{array}$ \\
\hline Symbol & &
\end{tabular}




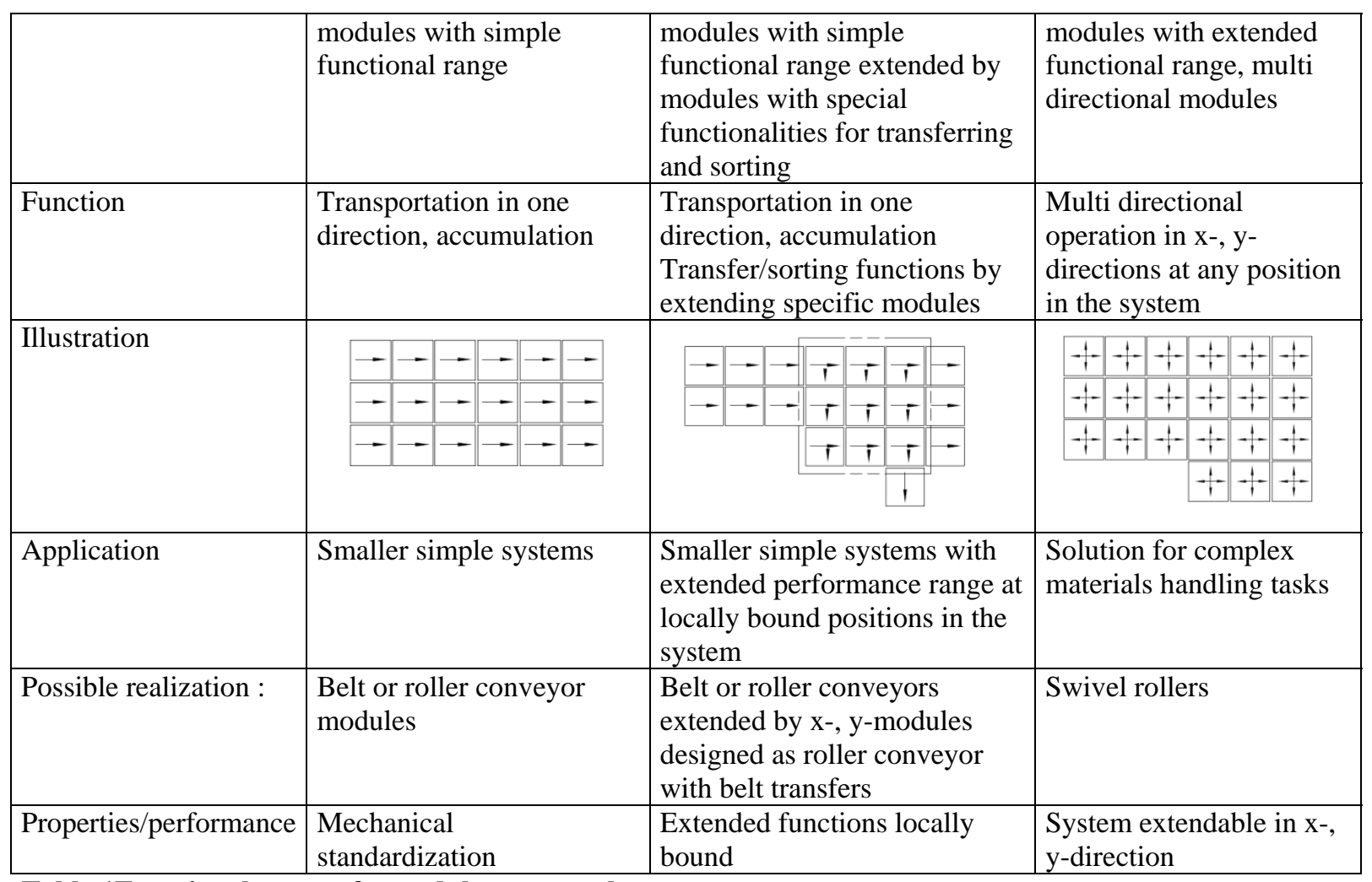

Table.1Functional range of a modular approach

The basic module needs to display high compatibility with the materials to be conveyed, especially at the interfacing points to adjacent modules. A higher degree of small scaling results in a higher number of interfaces between the modules. The relation between module size and conveying speed is an important aspect. The usual speed range of modern intralogistic conveying systems lies between 30 and $120 \mathrm{~m} / \mathrm{min}$. Special high performance sorting systems have even higher speeds.

For the controlling of the material flow tasks position detection and identification of transportation units are necessary. The detection by means of optical sensors is independent of the material specification of the transportation unit and is preferred to capacitive or magnetic sensors. The design and organization of the optical detection on the modules depends on the size and shape of the transportation unit in relation to the module size and to the number of modules combined by the control system. Optical proximity switches have proven beneficial in intralogistic applications and they are available in very small sizes. This solution in combination with fiber optics appears especially interesting. Saving space, this fiber optic detection can be implemented at the detection position on a small scaled module. The electronics can be set up separately from the detection point inside the module. Even new methods of data transfer by fiber optics can be used [FAH 08].

For the implementation of its own intelligence and an extended functionality it is necessary to equip each module with sensor systems.

The modularity of the elements should allow extension in various directions. Reflection and the one-way light barriers have the advantage of high reliability at low costs. However, as a disadvantage detection is only possible over the entire width or length of a conveyor. For extended functionalities it is necessary to detect smaller areas if, say, transportation units are lined up and next to each other on a module system with sort function. Detecting goods on each module is only possible if the optical sensors are integrated into each module and detect the transportation units from below. Dust deposit from above might be another disadvantage of these systems. 


\section{Module matrix}

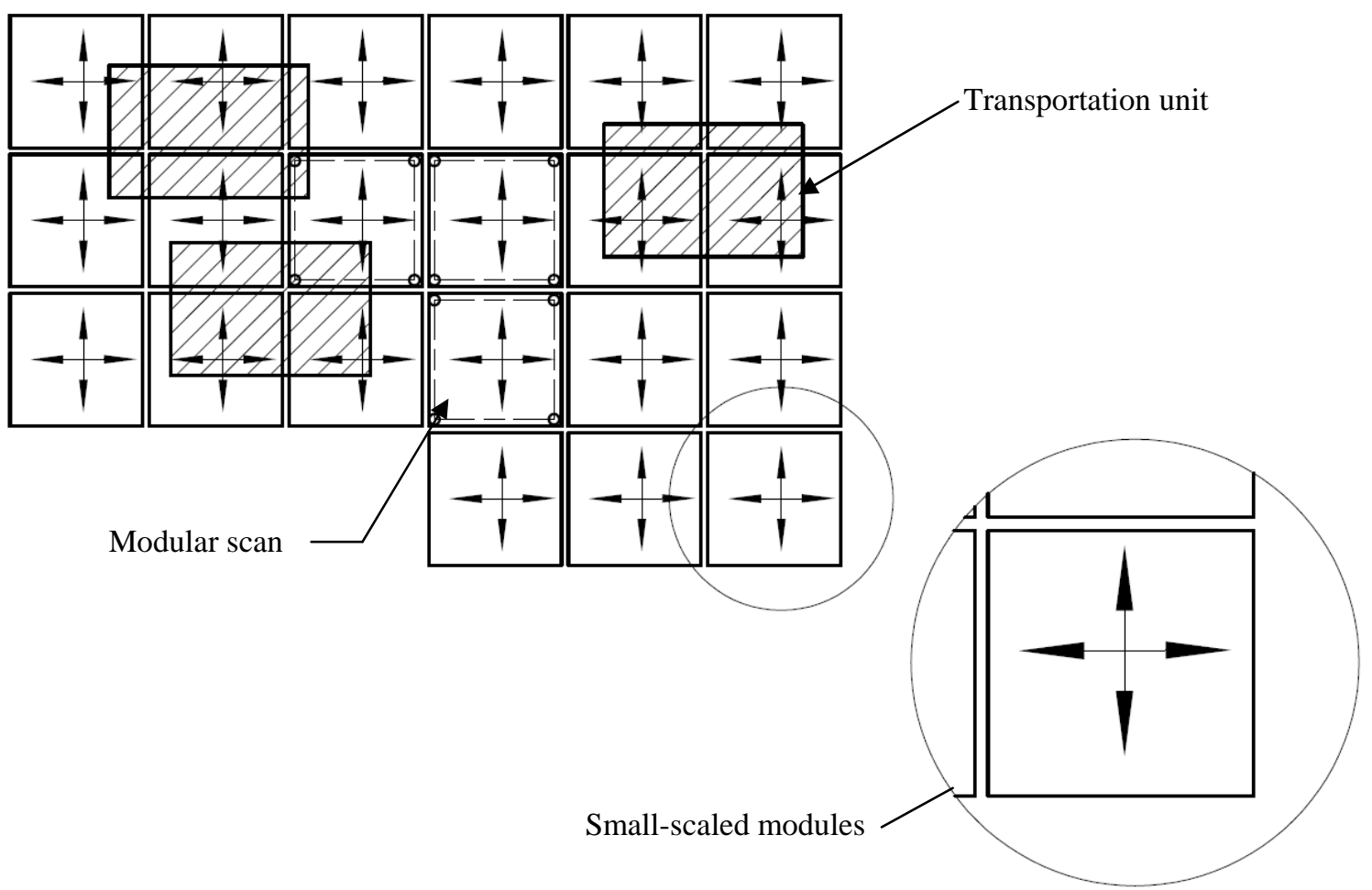

\section{Figure1: Modular systems}

In order to determine whether a module with , for example, square surface area is occupied, it would be ideal to detect all edges of a module. Here a completely new trend-setting technology could be used. In [FAH 08] a procedure to dispense of polymer fiber optics is described. In this connection optical polymers are used in order to integrate fiber optics into mechanical components. The polymer fiber optics can be brought into the surface of the small-scaled module directly in order to allow plane wide area detection.

For the power supply of the actors an interface concept appears to be suitable by means of which the drive supply is passed on by interfacing from module to module, by an energy bus, for instance. Non-contacting systems for energy transmission are already accomplished [BEU 99, BEU 01]. However, those systems are comparatively large and are disadvantageous to the efficiency. For the data processing bus systems will be used and further developed. A wireless communication might present an alternative possibility, like WLAN or ZigBee with standardized transmitter and receiver at every controlled module, for example.

Possible control models are currently examined in [OVE 09-01], [OVE09-02]. In the context of these studies, which are accomplished by the Institut für Transport und Automatisierungstechnik (ITA) of Leibniz University of Hanover in co-operation with Transnorm System GmbH, a three level control model with a superordinate control level for the entire logistics system is suggested. Among them the control level for individual flow of material functionalities such as sort procedures in union of logistics elements is located. In the subsystem level the control logic is distributed decentralized on the small-scale modules. The state of the system and subsystems and its change over time in these levels can be described wit a transition function. Part of the investigation is the possible linking of these transition functions. 


\section{Approaches based on existing technology}

In order to make the complexity of the solution identification clear and conceivable, one can avail oneself of appropriate solution identification methods [PAH 93] and search in suitable solution catalogs as [KOL 98, EWA 75, LIN 08, ROT 00]. Order patterns are used for systematic search, from which solutions can be derived and which, in turn, facilitate linkage. Figure 2 shows the exemplary procedure.
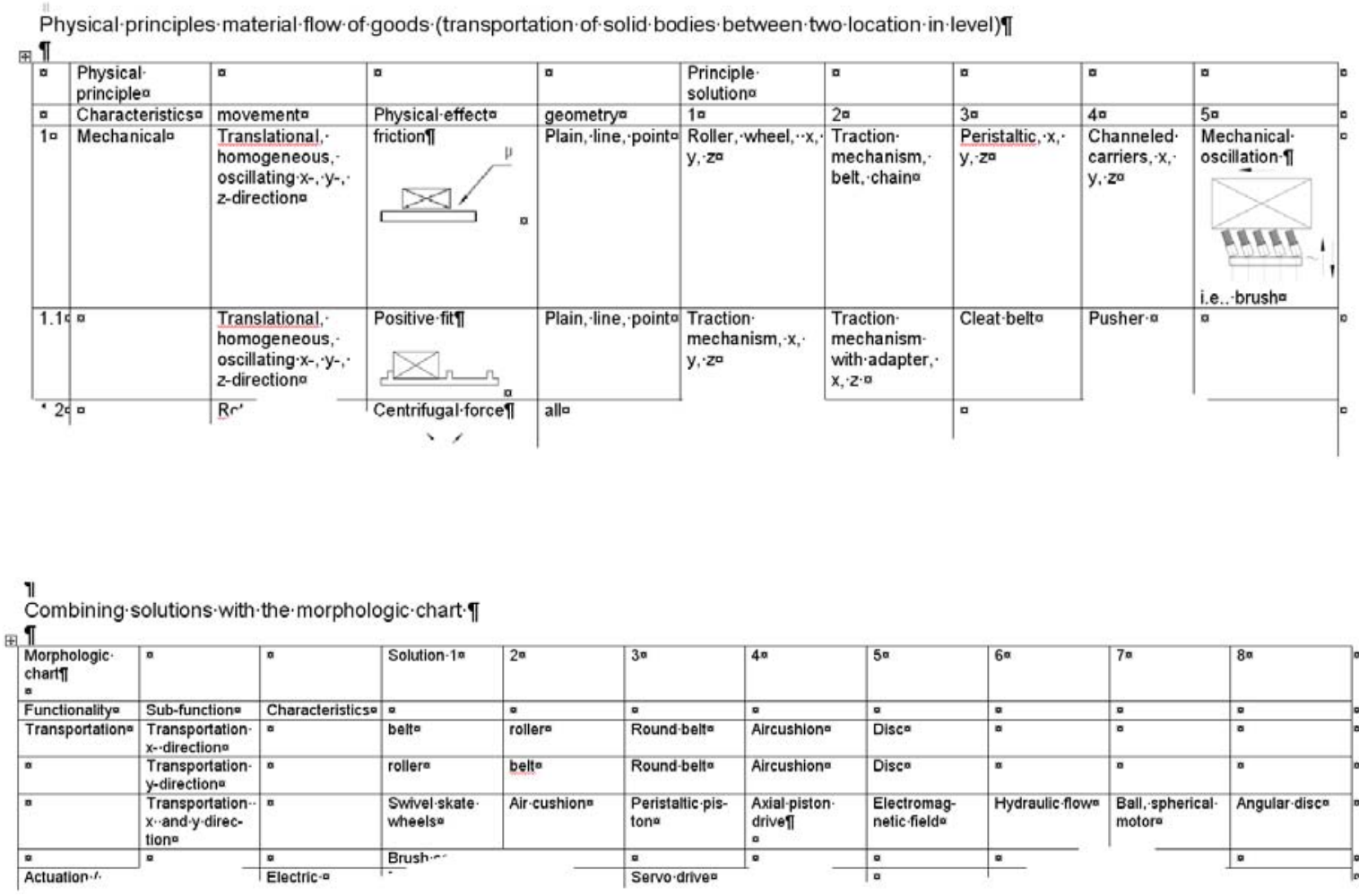

Choice and benchmarking of solution combination

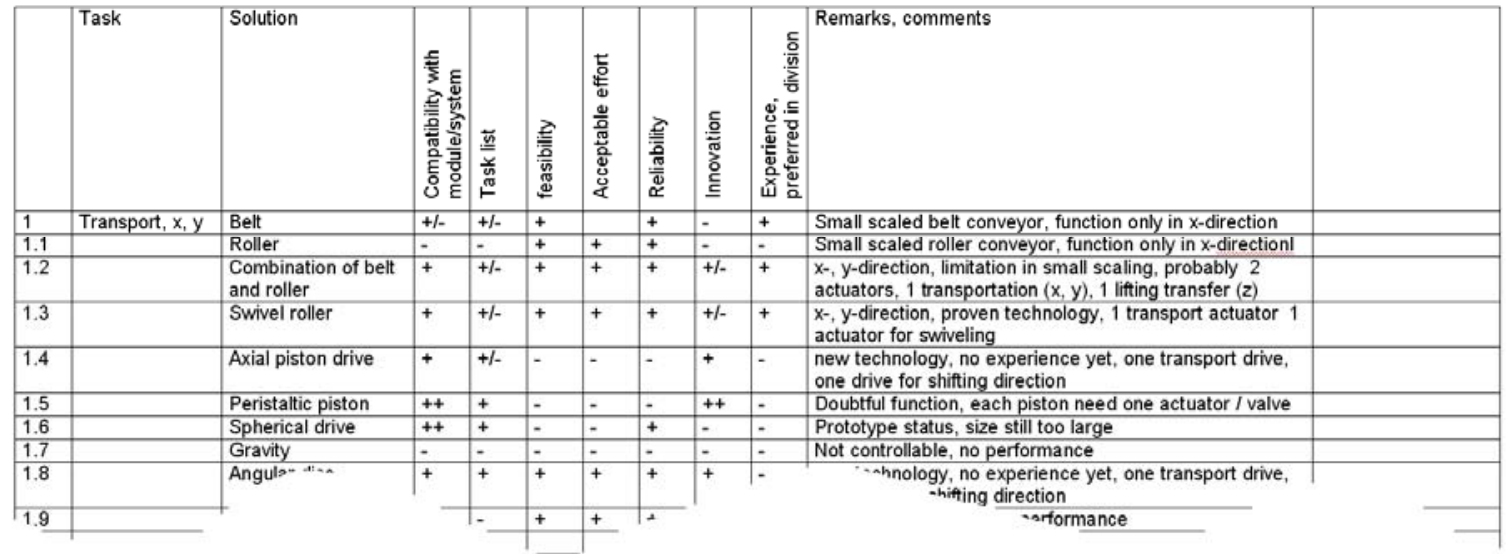

Figure 2: Resources for systematic solution determination, organization schemes 


\section{Belt Conveyor}

Small-scaled belt conveyor modules can be connected with each other. Depending upon size of the modules and the conveyed transportation units several modules can be utilized by a transportation unit in longitudinal as well as in transverse direction. In connection with small-scaled belt conveyor modules only functionality in conveying direction (x-direction) is given. Sorting tasks and discharges or transfer operations in y-direction are not possible unless the modules are very small in comparison to the size of the transportation unit, and transfer units can be placed between the belt conveyor modules. One possible design might be hoisting belt dischargers. As drive systems, depending on the size, smaller three-phase alternating current drives and direct current drives are used which are applicable in the form of roller drives.

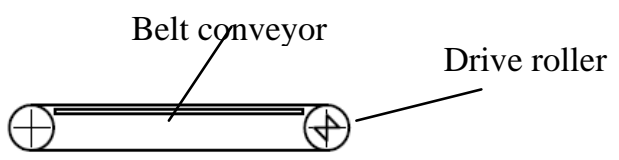

Figure 3:Schematic of a small-scaled belt conveyor

\section{Roller conveyors}

Regarding functionality and connectivity, discharge functionality is given in y-direction only by supplementing discharge modules between the rollers, very similar to belt conveyor modules. as mentioned before. The discharge module lifts up between the rollers and conveys to y-direction. In summary, this solution shows a bidirectional module, which corresponds to the mechanical requirements. As drive systems depending on the requested size three-phase alternating current drives and direct current drives are applicable in the form of roller drives.

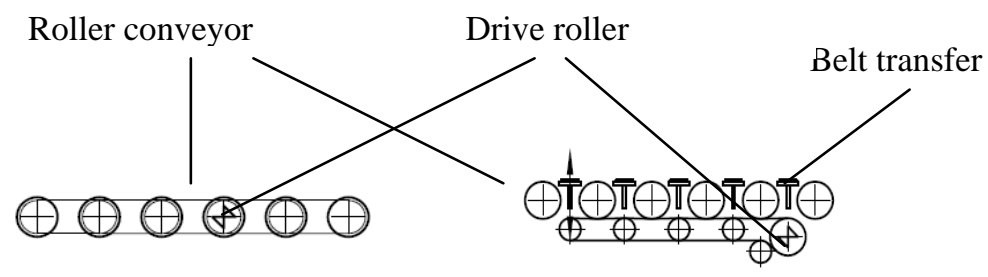

Figure 4:Schematic of a small-scaled roller conveyor

\section{Swiveling Rollers}

Swiveling rollers are ideally designed as roller drive. That means that the drive system is integrated in the roller. Preferably an adjustable small direct current drive is used which is stored in a swiveling- and supply-module (connection module) within the same drive system supply. For conveying and swiveling, two rollers as homogenously as possible specially designed actuators are necessary. The Combination of $n \times \mathrm{n}$ small-scaled swiveling roller elements and its connection to one module is shown in Figure.5 and Figure.6. Such elements also can simply be mechanically connected and, like it is currently applied on swiveling roller discharge systems, share one drive for conveying and for swiveling. This reduces the investment costs and substantially facilitates the realization.

An advantage of this solution compared to the solutions specified before is the sort output. Belt and roller modules with discharge systems display their y-functionality at an angle of $90^{\circ}$ to the main conveying direction. Sort functions with swiveling rollers are clearly more efficient, because the material flow can be turned back in arbitrary angles and thus can be distributed from the continuous material flow. It might also be possible to develop swiveling rollers driven by electric motors using conventional means which fulfill the given requirements of conveying and swiveling speed. Figure. 2 shows corresponding system designs. The developed conveyor modules are suitable for the connection of small-scaled conveyor systems because of their flexibility. A material flow system that consists of combinations of such conveyor modules is not competitive owing to its total costs. However, it might be shown that a combination of small-scaled conveyor systems can technically be realized and it shows a high potential for increasing the flexibility in intralogistic applications. 


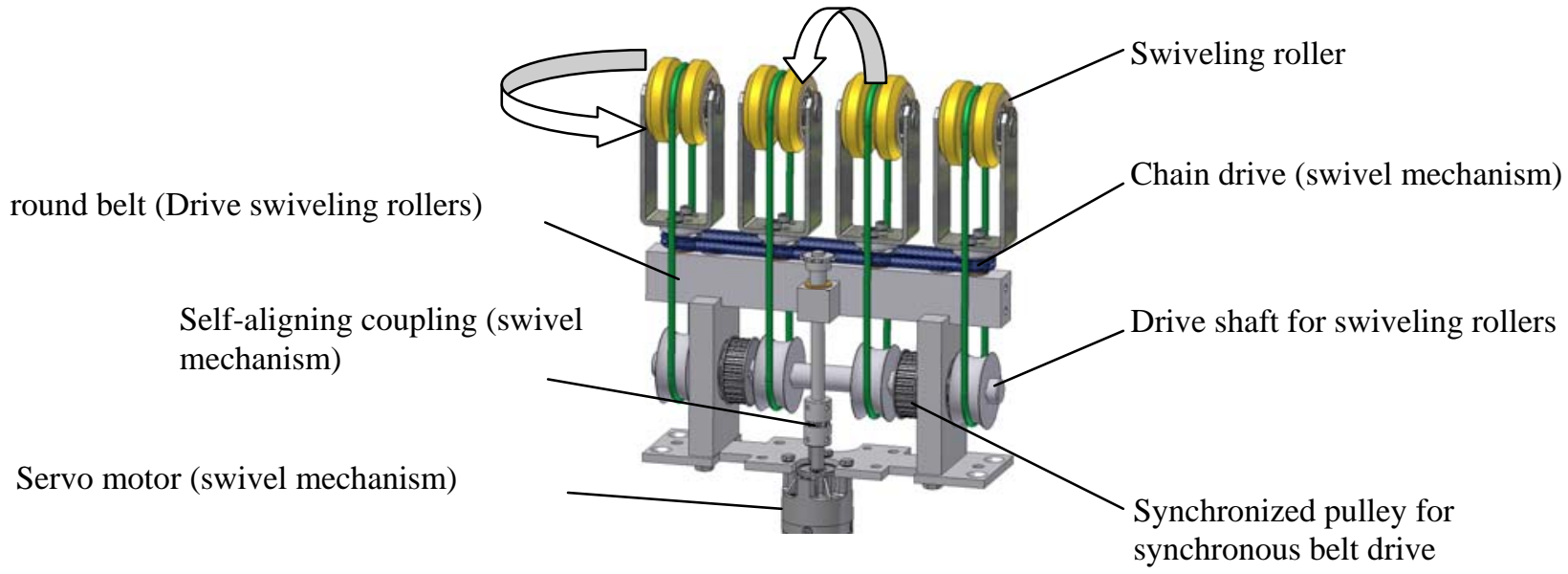

Small-scaled conveyor module with integrated sensors
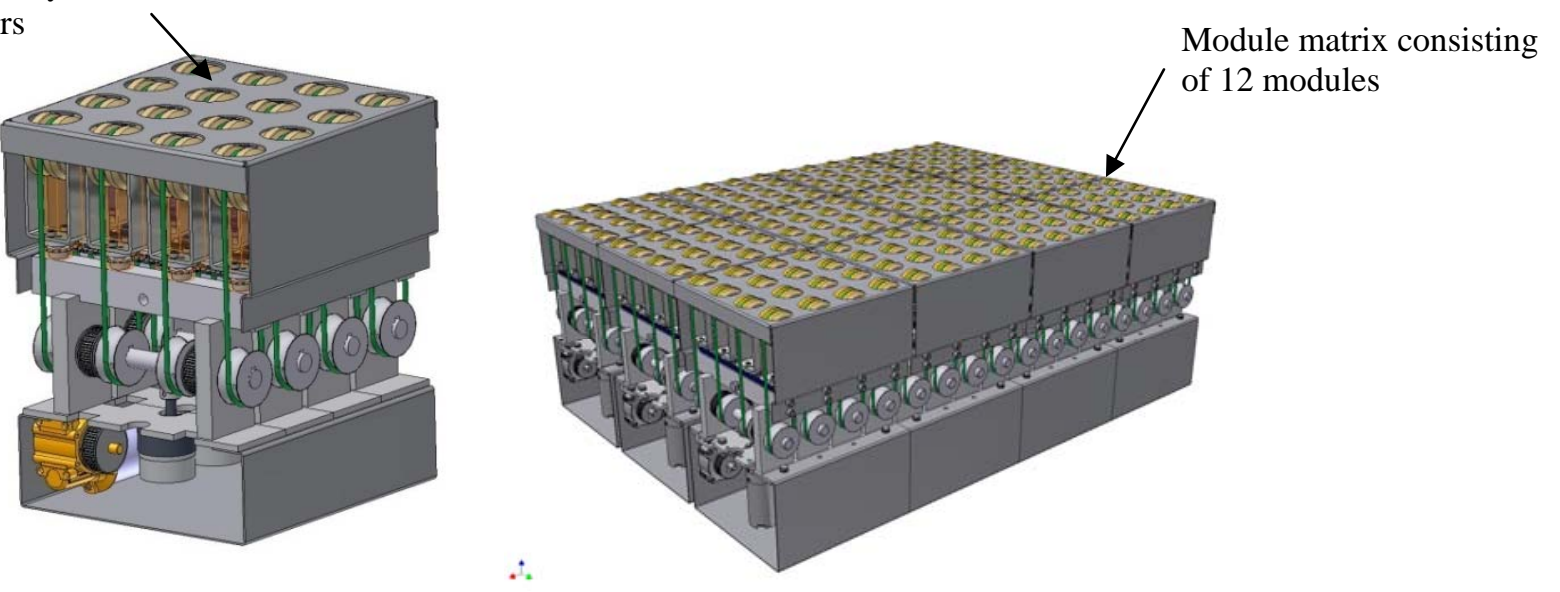

Figure.5: Concept study based on belt driven swiveling rollers 

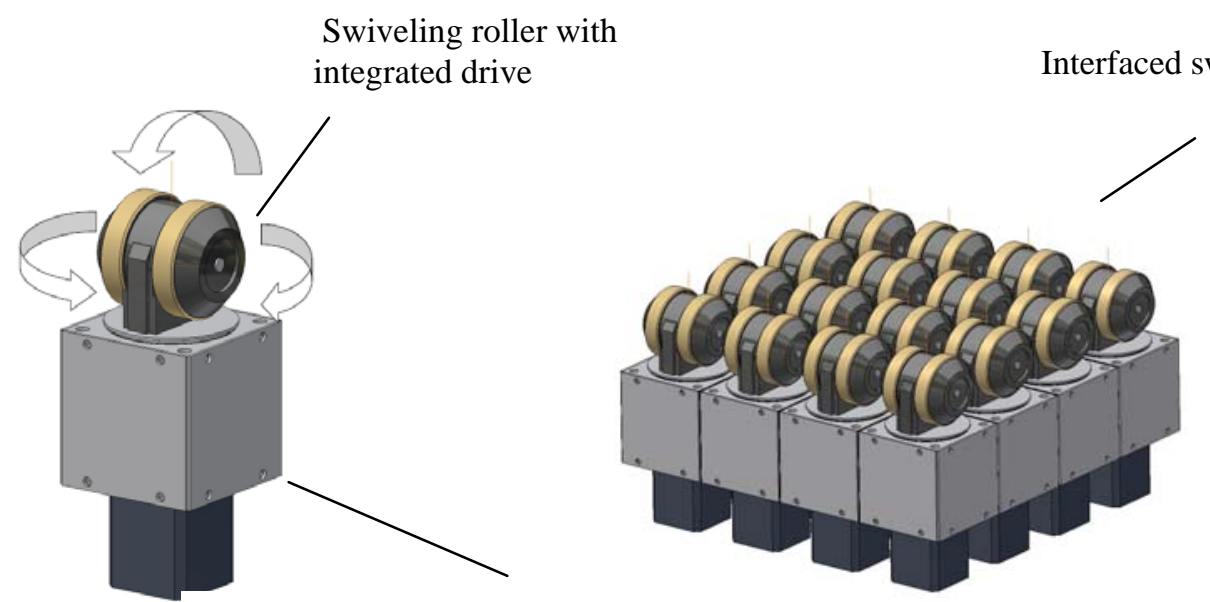

Base with swivel drive (servo motor)

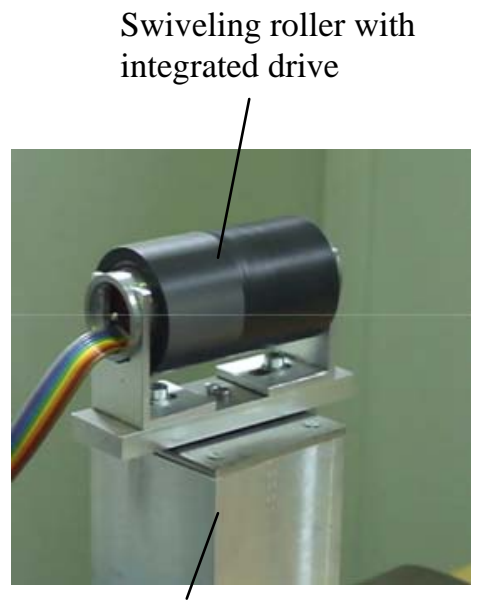

-Prototype Swivel roller with integrated electronic drive, ITA 2008

Base with swivel drive (servo motor)

Figure.6: Concept study based on swiveling rollers

\section{New approaches for the development of small-scaled modules}

In the following chapter new approaches for the development of small-scaled modules are presented and be examined on the basis of first concept studies.

\section{Axial-Piston Driver}

The idea of an axial or turning piston driver is based on the basic construction of an axial-piston pump. Concentrically and axially arranged pistons or tappets rotate in a disk around an axle and are controlled in their stroke by a swash plate. With rotation of the disk the deployed tappets carry forward the goods to be conveyed and retract again after contact with the material to be conveyed. By rotating the swash plate it can be determined at which angle of rotation the pistons reach their maximum stroke and thus the conveying direction can be set. A corresponding concept is shown in Figure.4. Due to the fact that this system concept represents a new approach for small-scaled modules, no practical experience is available at this time. A significant aspect regarding the applicability is the compatibility with common materials to be conveyed. The system makes special demands on the material to be conveyed due to the small and wide-spread contact area. The bottom of the goods must be very plane and solid. For example, plastic containers with plane bottom would be usable. The movement of the tappets describes a curve. The material to be conveyed is moved tangential to the curve in the point of contact. Due to the system design solutions surrounding noise reduction have to be considered, too. 


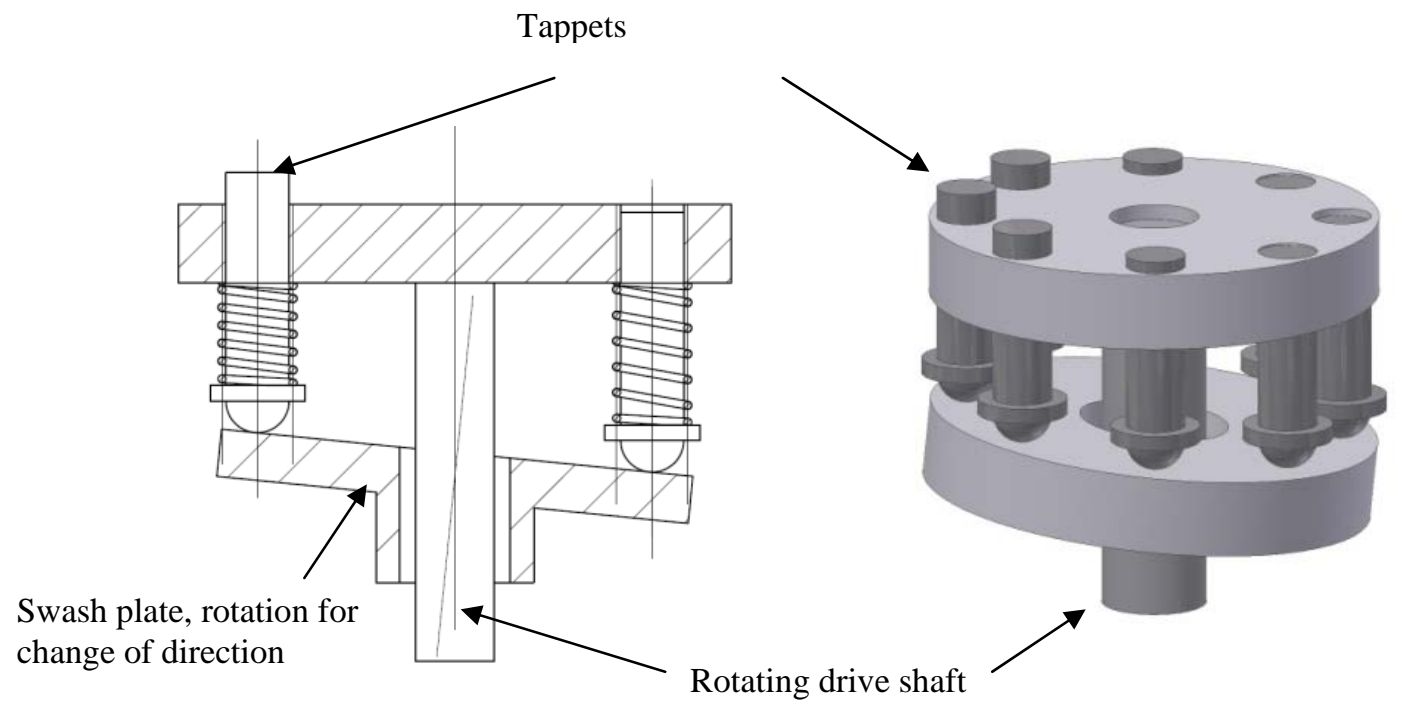

\section{Figure.2: Concept study of an axial-piston driver as conveyor module}

\section{Swash Plate}

The concept of a swash plate is the simplified principle of the presented axial piston driver. A rotationally symmetric disk inclined to the conveying level contacts the material to be conveyed at its highest, from the conveying level most prominent point and enables movement with rotation around the own axle. By turning the disk around the Z-axis, which is orthogonal to the conveying level, the most prominent point of the disk shifts around the Z-axis and the direction of the conveying changes. Thus a version with variable conveying direction is possible. A corresponding concept is shown in Figure.5.

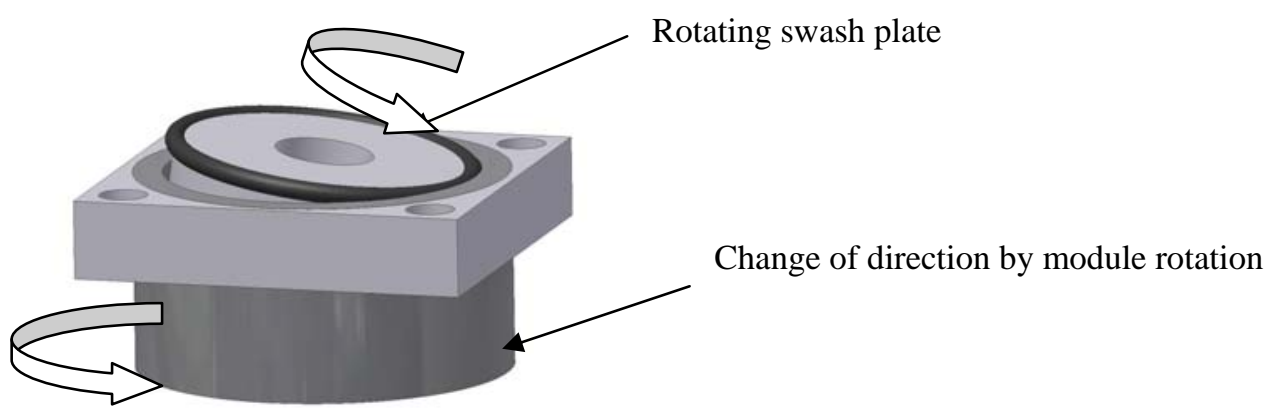

Figure.3: Concept study of a swash plate as conveyor module

By the tangential curve shaped movement in the point of contact deviations from the ideal conveying direction are possible. This disadvantage can be compensated, however, by adept arrangement of the elements, like alternately arranging left or right hand side inclined counter rotating elements in $\mathrm{x}$ - and $\mathrm{y}$-direction, for example. The concept of the swash plate offers the possibility of combining several swash plates to one module, in order to save drive systems or use conventional and larger drive system solutions.

\section{Summary}

Solving in-plant material flow problems, the approach of interfacing small sized modules offers a considerable economization potential. On the one hand the integrated intelligence in combination with local controlling and standardized interfaces reduces the control effort. The modules can easily be exchanged and used in any location of the system. Communication and control approaches for the interconnected modules are currently examined separately at the ITA within the project CogniLog [OVE09-01], [OVE09-02]. 
On the other hand we gain more geometric flexibility due to smaller sized modules. Identical modules create benefits in production and price. A multi directional working conveyor module, able to realize functions like sorting or change flow direction anywhere in the system is fundamental for a small sized identity. Some conveying technologies like swivel rollers offer promising approaches, new solutions will also be discussed.

Another important aspect is the possible initiation of a technology change especially in the field of drive system technology and components.

To benefit the small sized modules in a complete range more research will be necessary. In the field of mechanical conveying technique research for new methods of materials translocation has to increase, by which ultimately it is possible to design small sized multi directional modules. The control for these modules will be covered by local implemented intelligences and their communication. In the field of drive technology the use of mechatronic actuators will be examined.

\section{References}

[ARN 06] Arnold, D. (Hrsg.): Intralogistik - Potentiale, Perspektiven, Prognosen, Springer Verlag 2006 ISBN 3-540-29657-3

[BEU 01] Beumer, C.. Neuentwicklungen in der Logistik durch berührungslose Energieübertragung; Logistik für Unternehmen, 10/2001

[DEM 08] Dematic, Hersteller von Förderersystemen, modulares mechatronisches Stückgutfördersystem CL110, Katalogschrift

[DUB 05] Grothe, K.-H., Feldhusen, J. (Hrsg.): Dubbel, Taschenbuch für den Maschinenbau, Kapitel U5, Förderelemente und Fördersysteme für den innerbetrieblichen Materialfluß, Springer Verlag 2005 - ISBN 3-540-49714-5

[EWA 75] Ewald, O.: Lösungssammlungen für das methodische Konstruieren; VDI-Verlag, Düsseldorf 1975 - ISBN 3-18-400310-8

[FAH 08] Fahlbusch, T.: Dispensieren polymerer Lichtwellenleiter, Dissertation Institut für Transport- und Automatisierungstechnik, Leibniz Universität Hannover 2008 - ISBN: 978-3-939026-53-2

[FLE 05] Fleisch, E.; Mattern, F. (Hrsg.): Das Internet der Dinge - Ubiquitous Computing und RFID in der Praxis, Springer Verlag 2005 - ISBN 3-540-24003-7

[HOM 05] Ten Hompel, M., Schmidt, T.: Warehouse Management, Springer Verlag 2005 - ISBN 3-54022509-9

[HOM 06] ten Hompel, M.: Dezentrale Steuerung für Materialflußsysteme am Beispiel von Stückgutförderund sortieranlagen, Logistics Journal 2006 - ISSN 1860-7977

[JOD 06] Jodin, D., ten Hompel, M.: Sortier- und Verteilsysteme, Grundlagen, Aufbau, Berechnung und Realisierung; Springer 2006 - ISBN 3-540-29070-2

[KOL 98] Koller, R., Kastrup, N.: Prinziplösungen zur Konstruktion technischer Produkte; Springer-Verlag 1998 - ISBN 3-540-63060-0

[LIN 08] Lindemann, U.: Physikalische Effektesammlung; Lehrstuhl für Produktentwicklung, TU München

[OVE 05] Overmeyer, L., Vogler, S.: RFID: Grundlagen und Potenziale. Logistics Journal, S. 1-12, ISSN 1860-5923 (2005).

[OVE 07] Overmeyer, L.: Innovative Gestaltung von Intralogistik durch Kopplung kleinskaliger Systeme, 16. Deutscher Materialfluss-Kongress; VDI-Berichte 1978, S. 171-179. Düsseldorf: VDI Verlag, 2007. - ISBN 978-3-18-091978-2 
[OVE 09- $\quad$ Overmeyer, L.; Heiserich, G.; Falkenberg, S.; Jungk, A.: Automatische Konfiguration und 01] Optimierung von Materialflusssystemen durch kognitive Logistikmodule. In: VDI-Berichte Band 2066, 18. Deutscher Materialfluss-Kongress, München, 2009, S. 197-208.

[OVE 09- Overmeyer, L.; Heiserich, G.: Cognitive Transportation Modules for Adaptive Material Flow

02] Systems. In: Proc. Distributed Intelligent Systems and Technologies Workshop (DIST), St. Petersburg, 2009, S. 17-24.

[PAH 93] Pahl, G., Beitz, W.: Konstruktionslehre, Methoden und Anwendung, Springer-Verlag 1993 - ISBN 3-540-56194-3

[ROD 06] Roddeck, W.: Einführung in die Mechatronik, Teubner Verlag 2006 - ISBN 3-8351-0071-8

[ROT 00] Roth, K.: Konstruieren mit Konstruktionskatalogen, Springer-Verlag 2000 - ISBN 3-540-67142-0

[SEI 05] Seifert, W., RFID in der Logistik, Deutscher Verkehrsverlag 2005 - ISBN 3-871-54322-5

[TRA 08] Transnorm System GmbH, Hersteller von Fördersystemen, Moduline, modulares Fördertechniksystem, Katalogblätter

[WOL 07] Wolf-Kluthausen, H. (Hrsg.): Jahrbuch Logistik 2007, free beratung Gesellschaft für Kommunikation im Marketing GmbH, Unit Logistik, 2007 - ISBN 3-9809412-3-X 